NOTES

\title{
Determination of Glass Transition Temperatures of Cholesteryl Methacrylate-Methyl Methacrylate Copolymers by Gas Chromatography
}

\author{
Kikuo ShōJI, Yukio NAKAJIMA, Eiichi UEDA, \\ and Masatami TAKEDA \\ Department of Chemistry, Faculty of Science, Science University of Tokyo, \\ Kagurazaka, Shinjuku-ku, Tokyo 162, Japan
}

(Received November 15, 1984)

\begin{abstract}
KEY WORDS Gas Chromatography / Thermotropic Liquid Crystalline Polymer / Specific Retention Volume / Retention Diagram / Glass Transition Temperature /
\end{abstract}

Since Lavoie and Guillet ${ }^{1}$ measured the glass transition temperatures $\left(T_{\mathrm{g}}\right)$ of poly(vinyl chloride), polystyrene and poly(methyl methacrylate), the inverse gas chromatographic method (IGC) has been used for studying the physical properties of polymers. Using this method, studies on the small molecular liquid crystals have been reported by Matire et al., ${ }^{2}$ Willey et al., ${ }^{3}$ and Shōji et al., ${ }^{4}$ etc. However, this method has not yet been applied to thermotropic liquid crystalline polymers.

This study shows that the reproducible $T_{\mathrm{g}}$ of a copolymer can be determined by the IGC method from the retention diagram of decane for copolymers.

A differential scanning calorimetry (DSC) did not give correct $T_{\mathrm{g}}$ of cholesteryl methacrylate(ChMA)-methyl methacrylate(MMA) copolymers, because of poor reproducibility.

\section{Materials}

All the solvents employed were distilled prior to use. Cholesterol was used without further purification. The ChMA was prepared by reacting cholesterol with methacryloyl chloride in a solvent mixture of ether and toluene (1:1 by volume) at $80^{\circ} \mathrm{C}$ for $24 \mathrm{~h}$. The reaction mixture was then poured into methanol and the precipitated product was isolated with a yield of $63 \%$. White needle-like crystals $(\mathrm{mp}$ $107.5^{\circ} \mathrm{C}$ ) were obtained by three repeated precipitations.

The IR spectra of ChMA were measured with a Nippon Bunko 403-G spectrophotometer. ${ }^{1} \mathrm{H}$ NMR and ${ }^{13} \mathrm{C}$ NMR spectra were obtained with a JEOL FT-100. The monomer was soluble in benzene, chloroform and ether but insoluble in methanol and acetone.

\section{Solution Polymerization}

The homopolymerization of ChMA and copolymerization of ChMA-MMA were carried out by the method of Blumstein et al. ${ }^{5}$ for comparison of $T_{\mathrm{g}}$ data. The polymerization was carried out in a benzene solution (total monomer concentration: $0.1 \mathrm{moll}^{-1}$ ) at $60^{\circ} \mathrm{C}$, using azobisisobutyronitrile (AIBN) as the initiator $\left(0.01 \mathrm{moll}^{-1}\right)$ for $24 \mathrm{~h}$. The copolymers were precipitated from the benzene solution into methanol and the remaining monomer in the product was completely removed by ether extraction. The products were dried at room temperature under vacuum.

The composition of the copolymers was 
determined from the ${ }^{1} \mathrm{H}$ NMR spectra. All the copolymers were soluble in benzene, chloroform, carbon tetrachloride, and THF but insoluble in methanol and ether.

\section{Molecular Weight}

Measurements of the number-average molecular weight $\left(M_{n}\right)$ of the copolymers were made by gel-permeation chromatography with the apparatus of Waters Associates GPC-200, under the following conditions: solvents, tetrahydrofuran (THF); polymer concentration, 0.02 or $0.025 \%$; temperature, 40 or $60^{\circ} \mathrm{C}$; column, polystyrene gel $\left(8.5 \times 10^{3} \mathrm{~A}\right)$; standard materials, polystyrenes. The $M_{n}$ of copolymers are listed in Table I.

\section{Inverse Gas Chromatography}

The gas chromatographic experiments were carried out with a Yanaco, G-180 model, equipped with a thermal conductivity detector (recorder sensitivity; $1 \mathrm{mV}$ ). The column was a stainless steel tube $75 \mathrm{~cm}$ long and $4 \mathrm{~mm}$ in outer diameter. Helium was employed as the carrier gas whose flow rate was controlled to $60 \mathrm{ml} \mathrm{m^{-1 }}$, using a precision auto bubble

Table I. Properties of ChMA-MMA copolymers

\begin{tabular}{ccc}
\hline \multirow{2}{*}{$\begin{array}{c}\text { Mol. fraction } \\
\text { of ChMA }\end{array}$} & Yield & \\
\cline { 2 - 3 } & $\%$ & $M_{n}$ \\
\hline 0.92 & 83.5 & 80200 \\
0.85 & 68.9 & 72800 \\
0.72 & 90.4 & 45000 \\
\hline
\end{tabular}

Table II. Column parameters for ChMA-MMA copolymers

\begin{tabular}{cccc}
\hline \multirow{2}{*}{$\begin{array}{c}\text { Colum } \\
\text { No. }\end{array}$} & Content of ChMA & & Column loading \\
& $\mathrm{mol} \%$ & $\mathrm{~g}$ \\
\hline 1 & 92 & 0.7562 \\
2 & 85 & 0.7634 \\
3 & 72 & 0.7057 \\
\hline
\end{tabular}

flow meter (Standard Technology, SF-11M model). The support was a Chromosorb-G AW DMCS (60-80 mesh). The copolymer was dissolved in benzene, and then the support was added. The column filler covered with a thin film of the copolymer, was prepared by slowly evaporating the solvent. The solvent was completely removed under vacuum. $20 \mathrm{wt} \%$ loading of copolymer was employed, on the basis of the results obtained for the low molecular liquid crystals. ${ }^{4}$ The amount of copolymer deposited on the support was determined by gravimetric measurement. The gas flow rate was $60 \mathrm{ml} \mathrm{min}^{-1}$. Decane as the probe molecule without further purification was injected into the gas flow with a $0.1 \mu \mathrm{l}$ capacity micro syringe from Precision Sampling Co.

The relative retention time of decane was estimated in comparison with that of air, and the relative retention volume $\left(V_{\mathrm{r}}\right)$ was calculated from the relative retention time and flow rate of carrier gas. It is known that $V_{\mathrm{r}}$ significantly depends on the amount of injected solute, but $V_{\mathrm{r}}$ should be constant according to Henry's law at infinite dilution. Since the peak height was proportional to the amount of injected solute, $V_{\mathrm{r}}$ at infinite dilution $\left(V_{\mathrm{r}}^{0}\right)$ was determined by extrapolating the peak height to zero. The extrapolation corresponded to that in the low concentration region of probe molecule proposed by Nakajima et al. ${ }^{12}$ Moreover, $V_{\mathrm{r}}^{0}$ was reduced to the specific retention volume $\left(V_{\mathrm{g}}^{0}\right)$, and $V_{\mathrm{g}}^{0}$ defined by equation 1 was calculated.

$$
V_{\mathrm{g}}^{0}=273 V_{\mathrm{r}}^{0} / T W
$$

where $T$ is the column temperature $(\mathrm{K})$ and $W$, the weight of coated polymer.

\section{Retention Diagrams of Decane for the Copolymers}

The partition of a solute molecule between the moving and stationary phases is expressed in terms of $V_{\mathrm{g}}^{0}$ in gas chromatography, and is a characteristic parameter of the solute-solvent 
system investigated. A plot of logarithmic $V_{\mathrm{g}}^{0}$ versus the reciprocal absolute temperature, the so called retention diagram, must be straight unless a change occurs in the state of the stationary phase, such as that from solid to liquid. This is because the slope is closely related to the heat of solution.

Figure 1 shows the retention diagram of decane for the ChMA-MMA copolymer. The plots are linear, although they deflect just at temperatures corresponding to $T_{\mathrm{g}}$.

In gas liquid chromatography in which bulk sorption is due only to the retention mechanism, $V_{\mathrm{g}}^{0}$ should be independent of the mass of stationary phase. Similarly, in gas solid chromatography, the meaningful datum is the surface retention volume, that is, the retention volume per unit surface area of the absorbent. It has been shown that, when both effects are present, retention data for a low molecular weight stationary phase can be satisfactorily represented by the following relation. ${ }^{6}$

$$
V_{\mathrm{r}}=K_{\mathrm{b}} W_{1}+K_{\mathrm{a}} A_{1}
$$

where $V_{\mathrm{r}}$ is the retention volume, $K_{\mathrm{b}}$ and $K_{\mathrm{a}}$, the partition coefficients for the bulk sorption and surface adsorption, and $W_{1}$ and $A_{1}$ are the mass and surface area of stationary phase. If both retention mechanisms are operative in the stationary phase near $T_{\mathrm{g}}$, eq 2 should account for the retention diagram of crystalline polymers.

In this experiment, the $N$-shaped retention diagram could not be observed, but the diagram showed two straight lines having different slopes shown in Figure 1; similar linear plots were obtained in the case of copolymers containing 72, 85 and $92 \mathrm{~mol} \%$ of ChMA.

$V_{\mathrm{g}}^{0}$ linearly decreased with increasing temperature until the temperature corresponding to $T_{\mathrm{g}}$, and then $V_{\mathrm{g}}^{0}$ plots decreased along with another linear line as shown in Figure 1. A point of discontinuity was obtained as an intersection of the two straight lines.

In the case of small molecular liquid crys-

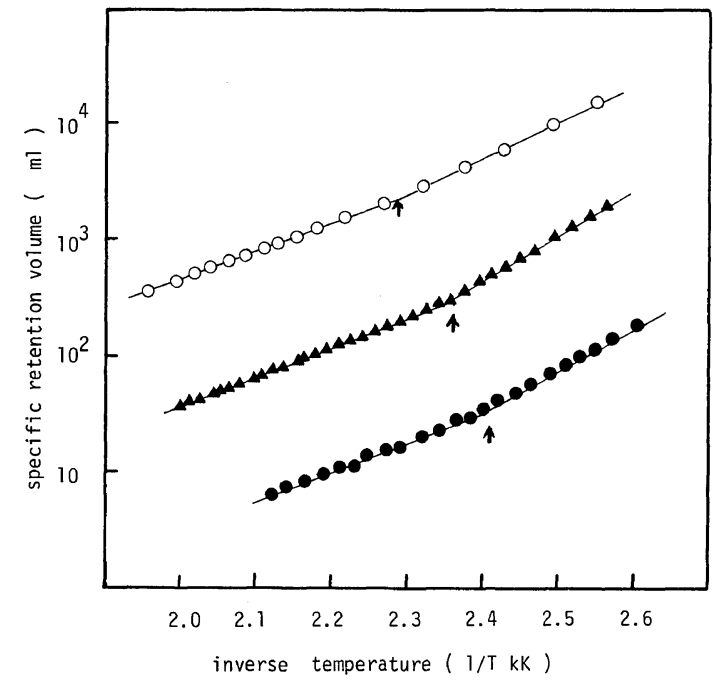

Figure 1. Temperature dependence of specific retention volume $\left(V_{\mathrm{g}}^{0}\right)$ of decane for ChMA-MMA copolymers. O, ChMA-MMA $(0.72 / 0.28) ; \boldsymbol{\Delta}$, ChMAMMA (0.85/0.15); O, ChMA-MMA (0.92/0.08).

Table III. Least squares analysis of the retention data

\begin{tabular}{|c|c|c|c|c|c|}
\hline \multirow{2}{*}{$\begin{array}{l}\text { Colum } \\
\text { No. }\end{array}$} & \multirow{2}{*}{$\frac{\mathrm{ChMA}}{\%}$} & \multicolumn{2}{|c|}{$\begin{array}{l}\text { Correlation } \\
\text { coefficients }\end{array}$} & \multirow{2}{*}{$\frac{\text { Intersection }}{{ }^{\circ} \mathrm{C}}$} & \multirow{2}{*}{$\frac{T_{\mathrm{g}}^{5,11}}{{ }^{\circ} \mathrm{C}}$} \\
\hline & & $\begin{array}{l}\text { at low } \\
\text { temp }\end{array}$ & $\begin{array}{l}\text { at high } \\
\text { temp }\end{array}$ & & \\
\hline 1 & 92 & 0.998 & 0.997 & 162 & 167 \\
\hline 2 & 85 & 0.999 & 0.998 & 150 & 160 \\
\hline 3 & 72 & 1.000 & 0.995 & 145 & 148 \\
\hline
\end{tabular}

tals, ${ }^{2-4}$ the $N$-shaped retention diagram could not be observed but the transition occurred at the point of discontinuity in the straight line.

In Figure 1, the copolymer containing the more rich in ChMA tends to show more indistinct discontinuity, probably because the homopolymers of cholesteryl methacrylate ${ }^{7-9}$ are amorphous.

Since it is not necessarily confirmed that the discontinuity from the retention diagram corresponds to the $T_{\mathrm{g}}$ of copolymer, the discontinuities were compared with the $T_{\mathrm{g}}$ values estimated from the deformation test by Blumstein et al..$^{5,11}$ in Table III. 
Although a considerable difference is observed for the sample of $85 \mathrm{~mol} \%$ ChMA, it may be assumed that both values are closely related to each other.

On of the authors reported that these copolymers began to show a mesomorphic state from the temperature of $T_{\mathrm{g}}{ }^{10}$ Even if the copolymers are amorphous, the thermodynamically stable mesophase may be easily formed in the molten state by the interaction between mesogenic groups.

Acknowledgement. The authors should like to express their appreciation to Professor Kazuyoshi Iimura and Professor Kenzi Tamaru of the Science University of Tokyo for their helpful comments.

\section{REFERENCES}

1. A. Lavoie and J. E. Guillet, Macromolecules, 2, 443 (1969).
2. L. C. Chow and D. E. Martire, J. Phys. Chem., 75, 13 (1971).

3. D. G. Willey and G. H. Brawn, J. Phys. Chem., 76, 1 (1972).

4. K. Shoji, T. Ishiji, and M. Takeda, Nippon Kagaku Kaishi, 4 (1980).

5. E. C. Hsu, S. B. Clough, and A. Blumstein, J. Polym. Sci., B, 545 (1977).

6. R. L. Martin, Anal. Chem., 33, 347 (1961).

7. Y. Tanaka, S. Kabaya, Y. Shimma, A. Okada, Y. Kurihata, and Y. Sakakibara, J. Polym. Sci., B, 10, 261 (1972).

8. H. Saeki, K. Iimura, and M. Takeda, Polym. J., 3, 414 (1972).

9. A. C. DeVisser, K. de Groot, J. Teyen, and A. Bantjes, Polym. Lett., 10, 851 (1972).

10. K. Iimura, T. Uchida, and M. Takeda, Rep. Prog. Polym. Phys. Jpn., 23, 275 (1980).

11. A. Blumstein, Y. Osada, S. B. Clough, E. C. Hsu, and R. B. Blumstein, ACS Symposium Series, 74, 60 (1978).

12. T. Nakajima and F. Ogasawara, Sen-i Gakkaishi, 39, T-408 (1983) 